\title{
Neurochemical and Physiological Effects of Cocaine Oscillate with Sequential Drug Treatment: Possibly a Major Factor in Drug Variability
}

Seymour M. Antelman, Ph.D., Anthony R. Caggiula, Ph.D., Susan Kiss, B.S., David J. Edwards, Ph.D., Donna Kocan, and Richard Stiller, Ph.D.

Variability in response to drug treatment is a poorly understood problem with severe consequences for both the individual and the health care delivery system. Our data suggest that one source of variability may be inherent in the way physiological systems normally respond to repeated drug exposures. We report that for a wide array of endpoints-amphetamine-evoked, in vitro striatal dopamine efflux, amphetamine and $\mathrm{K}^{+}$-evoked efflux of heart norepinephrine and nonevoked plasma levels of corticosterone and glucose-repeated, in vivo cocaine (15 $\mathrm{mg} / \mathrm{kg}$ IP) administration to male rats precipitated successive oscillations in the magnitude or direction of the organism's responsiveness to subsequent cocaine administration. This capacity of cocaine to produce oscillations in response to successive administrations appears to be due to its foreign/stressful aspect rather than its specific pharmacological properties.

[Neuropsychopharmacology 12:297-306, 1995]
KEY WORDS: Cocaine; Dopamine release; Norepinephrine release; Corticosterone; Stress; Striatum; Heart;

Oscillation

Remarkable variation in vulnerability to the physiological and behavioral effects of psychomotor stimulants clouds understanding of these drugs of abuse. For example, the doses of cocaine (COC) resulting in severe toxic reactions in humans have been reported to vary almost 14-fold (Van Dyke and Byck 1977), whereas

From the Department of Psychiatry (SMA, SK, DK), Western Psychiatric Institute and Clinic, University of Pittsburgh School of Medicine; Biopsychology Program, Department of Psychology, University of Pittsburgh and Pittsburgh Cancer Institute (ARC, SMA); Department of Pharmacology/Physiology (DJE), University of Pittsburgh School of Dental Medicine, Department of Anesthesiology (RS), University of Pittsburgh School of Medicine.

Address correspondence to: Seymour M. Antelman, Ph.D., Department of Psychiatry, Western Psychiatric Institute and Clinic, University of Pittsburgh School of Medicine, 3811 O'Hara Street, Pittsburgh, PA.

Received February 25, 1994; revised October 26, 1994; accepted November 7, 1994. doses of amphetamine (AM) resulting in psychosis were found to diverge by a factor of approximately 12 in one study (Bell 1973) and 48 in another (Connell 1958). Extreme variability in response to these agents has also been seen in animals (Ranje and Ungerstedt 1974; see Robinson 1988 for review). Indeed, variability has become an important issue in the study of sensitization (Robinson 1988). While reports in this research area predominantly suggest that the effects of repeated COC or AM enhance dopamine (DA) efflux (Kalivas and Stewart 1991; Robinson and Becker 1986; Zahniser and Peris 1992) from striatal and/or mesolimbic brain regions, an increasing number also report the opposite, that is, that these agents decrease DA release (e.g., Kalivas and Duffy 1993; Segal and Kuczenski 1992a, 1992b; Zahniser and Peris 1992).

Recent research from this laboratory suggests that one source of this variability may be the inherent tendency of physiological systems to compensate for repeated drug treatment. Such compensations may, under some circumstances, result in successive oscillations 
in the magnitude and/or direction of subsequent drug effects.

In one series of studies, we found that while ethanol (ETOH) administered to rats once, either minutes or weeks before sacrifice, markedly decreased the ability of AM to release DA from brain slices of the corpus striatum, the combination of these treatments significantly reversed the effect of either one alone (Antelman et al. 1992; Caggiula et al. submitted). That is, it "normalized" DA efflux almost back to control levels. These findings suggest that when a drug is given repeatedly, each administration changes the response of the organism to the next administration of the drug, possibly by altering the baseline on which the next treatment acts. Since two administrations virtually cancel the influence of a single drug treatment, we hypothesized that a three-chain sequence might reinstate the original drug effect (i.e., the drug effects would oscillate).

The first experiment of the present paper tested this hypothesis for the effects of COC on striatal DA efflux. We measured the effects of repeated, intermittent COC administration in the rat on AM-evoked in vitro efflux of DA from striatal slices. A complete replication of this study was also conducted 2 years later and is presented as the last experiment in the paper. In Experiment 2, the generality of oscillation induced by repeated drug administration was explored by assessing the effects of sequential $\mathrm{COC}$ administration on $\mathrm{Am}$ - and $\mathrm{K}^{+}$evoked norepinephrine (NE) release from the heart and on nonevoked plasma corticosterone (CORT) and glucose (GLUC) levels. The third study determined whether a nonpharmacological stressor, immobilization, could substitute for cocaine in producing the oscillation effect on AM-induced DA release from the striatum.

\section{METHODS}

\section{Subjects}

Male Sprague-Dawley rats were obtained from a local supplier, Zivic-Miller, and weighed 200 to $225 \mathrm{~g}$ at the start of experimentation. They were double-housed in wire-mesh cages and maintained in a temperature- and humidity-controlled colony room on a natural day-night cycle, with lights on at 0600 and off at 1800 hours. One week of adaptation preceded the onset of experimentation. Food and water were available ad libitum, and animals were weighed daily to ensure that growth was proceeding normally and to prevent the hyperreactivity that occurs when animals are left unhandled for long periods. All experiments were conducted between 0900 and $\mathbf{1 3 0 0}$ hours in order to minimize the influence of circadian variations, and each group in a given study was represented on all days of experimentation.

\section{In Vitro Dopamine and Norepinephrine Efflux Procedure}

Amphetamine-evoked DA efflux from rat striatal slices was determined using the method of Snyder et al. (1990). Briefly, freshly dissected striata were cut with a Mcllwain tissue chopper to obtain $350-\mu \mathrm{m}$-thick coronal slices. Striatal slices from six rats, randomly chosen from different experimental groups, were superfused simultaneously in each of the six chambers of a Brandel superfusion system. This procedure was repeated several times per day for a maximum of 4 consecutive days, depending on the number of animals in the experiment. Slices were then perfused with Krebs buffer bubbled with $95 \% \mathrm{O}_{2}-5 \% \mathrm{CO}_{2}$ and containing $113 \mathrm{mM} \mathrm{NaCl}, 4.7 \mathrm{mM} \mathrm{KCl}, 2.5 \mathrm{mM} \mathrm{CaCl}, 1.2 \mathrm{mM}$ $\mathrm{MgSO}_{4}, 25 \mathrm{mM} \mathrm{NaHCO} 3,1.2 \mathrm{mM} \mathrm{KH}_{2} \mathrm{PO}_{4}, 11.5 \mathrm{mM}$ glucose, $0.3 \mathrm{mM}$ ascorbic acid, at a rate of $0.24 \mathrm{ml} / \mathrm{min}$ ute at $37^{\circ} \mathrm{C}$. Following a 60 -minute equilibration period, nine fractions were collected at 5 -minute intervals into disposable plastic tubes containing $50 \mu \mathrm{l}$ of $0.1 \mathrm{~N}$ perchloric acid and $1 \mathrm{ng}$ of the internal standard, 3,4dihydroxybenzylamine. After the first two baseline fractions were obtained, DA efflux was evoked by $10 \mu \mathrm{M}$ AM added to the perfusion buffer for 5 minutes during the collection of fraction \#3, and six additional fractions (No. 4-9) were collected in order to wash out all of the catecholamine released by the drug. Tissue viability was verified at the end of experimentation by observing DA efflux in response to a $60-\mathrm{mM} \mathrm{KCl}$ challenge. At that point slices were removed from the tissue chambers and homogenized in $500 \mu \mathrm{l}$ of $0.1 \mathrm{~N}$ perchloric acid. An aliquot of each homogenate was then assayed for protein content (Lowry et al. 1951). The superfusate fractions were then stored at $-20^{\circ} \mathrm{C}$ until DA concentration was determined by HPLC with electrochemical detection. Dopamine was extracted from each superfusate by adding $50 \mathrm{mg}$ of alumina and $200 \mu \mathrm{l} 1 \mathrm{M}$ Tris buffer-EDTAsodium metabisulfite $(\mathrm{pH} 8.6)$. The alumina was washed twice with 0.1 Tris buffer $(\mathrm{pH} \mathrm{8.6)}$, and the catechols were eluted by adding $200 \mu 10.1 \mathrm{~N}$ perchloric acid. The samples were injected by a Waters WISP autoinjector onto a $5-\mu \mathrm{m}$ Biophase ODS column (mobile phase $0.1 \mathrm{M}$ chloroacetic acid, $2 \mathrm{mM}$ EDTA, $1.5 \mathrm{mM}$ octanesulfate and $13 \%$ methanol, pH3.2). The amperometric detector was set at an oxidizing potential of $0.7 \mathrm{~V}$ (vs. $\mathrm{Ag} / \mathrm{AgCl}$ ).

Norepinephrine efflux from the right atrium was determined using a similar procedure to that described above for striatal DA efflux, with the major exception that following AM-evoked efflux, $\mathrm{K}^{+}$-induced efflux was subsequently measured in the same tissue sample (using $25 \mathrm{mM} \mathrm{KCl}$ ). In addition, to measure $\mathrm{NE}$ by HPLC, the methanol concentration of the mobile phase was $4 \%$. 
Although we measured both basal catecholamine efflux and AM-evoked overflow in individual 5-minute fractions, we have reported only the total of AMinduced efflux in the Results. The basal efflux of DA and NE (expressed as $\mathrm{ng} / \mathrm{mg}$ protein) was calculated as the ratio of the average amount of the catecholamine in fractions No. 1, 2, and 9 to the amount of protein in the tissue slices. The basal (spontaneous) efflux of DA from striatal slices (approximately $0.2 \mathrm{ng} / \mathrm{mg}$ protein per 5 minutes) did not differ across treatment groups for each experiment. Similarly, the basal efflux of NE from the heart right atrium $(0.1 \mathrm{ng} / \mathrm{mg}$ protein) was unaffected by the various pretreatments.

Because of the delay from the time AM was added to the perfusion buffer until any catecholamine released by the drug reached the collection tubes, no increases in DA or NE were found in fraction No. 3. In general, catecholamine levels were elevated above baseline in fractions No. 4 through 7 or 8 , with the peak amount usually appearing in fraction No. 5 . However, the time course of catecholamine efflux was unaltered in any of the experiments, and therefore to simplify the Figures, only the total overflow is shown, rather than that measured in the individual fractions. Total AM-evoked efflux for each rat was determined by adding the six post-AM fractions (No. 3-8) and subtracting six times the mean baseline value (mean of No. 1, 2, and 9).

\section{Corticosterone}

Plasma CORT was measured by the competitive protein-binding radioassay of Murphy (1967). Trunk blood was collected upon decapitation by gentle swirling in a small beaker containing $200 \mu$ l of sodium heparin $(10,000$ USP units $/ \mathrm{ml})$. The blood samples were then centrifuged for 15 minutes and the plasmas removed by Pasteur pipette and stored at $-20^{\circ} \mathrm{C}$ until assayed. Each plasma sample $(10 \mu \mathrm{l})$ was pipetted into $0.5 \mathrm{ml}$ of ETOH in a centrifuge tube. After mixing and centrifuging, the supernatant fractions were transferred to small test tubes and evaporated to dryness. To each tube was added $1.0 \mathrm{ml}$ of $2 \%$ human plasma (the source of the corticosteroid-binding globulin) and ${ }^{3} \mathrm{H}$-corticosterone $(0.4 \mu \mathrm{Ci}$ in $\mathrm{ETOH})$. The tubes were then shaken and incubated at $45^{\circ} \mathrm{C}$ for 10 minutes. Unbound CORT was then removed by adsorption on $40 \mathrm{mg}$ of Florisil. The amount of radioactivity in the supernatant (bound) fraction was determined by liquid scintillation counting.

\section{Plasma Glucose}

This was assayed by a glucose oxidase/peroxidase method (Trinder 1969), and automated with a Technicon AutoAnalyzer. Reagents were purchased in a kit from Boehringer Mannheim (\#124001). The method is based on the oxidation of GLUC in water to gluconic acid and hydrogen peroxide in the presence of glucose oxidase. Hydrogen peroxide reacts with phenol 4-aminophenazone in the presence of peroxidase to form a red dye. The concentration of the red dye is measured colorimetrically and is proportional to the GLUC concentration. Only "true GLUC" is measured, since other sugars (except for 2DG, which does not occur naturally in blood) do not react. The method is sensitive to about $10 \mu \mathrm{g} / \mathrm{dL}$ and is linear to $400 \mu \mathrm{g} / \mathrm{dL}$. The interassay coefficient of variation for replicate samples in our lab is about $2 \%$.

\section{Statistical Analysis}

Preliminary analyses indicated that there were no baseline differences between groups. For each experiment, the existence of group differences in stimulated efflux was first determined by subjecting measures of total evoked efflux (see above) to one-way analyses of variance (ANOVAs). This was followed by a limited number of comparisons between successive treatment conditions (e.g., one pretreatment vs. two pretreatments; two vs. three, etc.) using linear contrasts within the general linear model. All analyses were completed using SPSS.

\section{Experiment 1: Effects of Sequential Cocaine Administration on Amphetamine-Evoked Efflux of Striatal Dopamine}

Procedure. Rats were pretreated with a single injection of COC hydrochloride ( $15 \mathrm{mg} / \mathrm{kg}$ IP) at one of three time points: either 30 minutes, 1 week, or 2 weeks before sacrifice. Additional groups received sequential treatment of either two (e.g., 1 week +30 minutes) or three ( 2 week +1 week +30 minutes) COC injections. All groups were timed to be equally represented on the same sacrifice day.

Results and Discussion. Each pretreatment, when given alone, decreased AM-induced DA release (to $18-37 \%$ of control; Figure 1). However, when the 1-week pretreatment was combined with the 30-minute injection in other rats, the attenuation was itself significantly diminished (e.g., it returned to $57 \%$ of control in the 1-week/30-minute COC group), exactly as we had seen with ETOH (Antelman et al. 1992a; Caggiula et al. submitted). The combination of $\mathrm{COC}$ given at 2 weeks and 30 minutes before sacrifice showed a nonsignificant trend relative to COC given only 2 weeks earlier. Since the long-term effects of psychostimulants such as COC and AM have repeatedly been shown to be interchangeable with those of nonpharmacological 


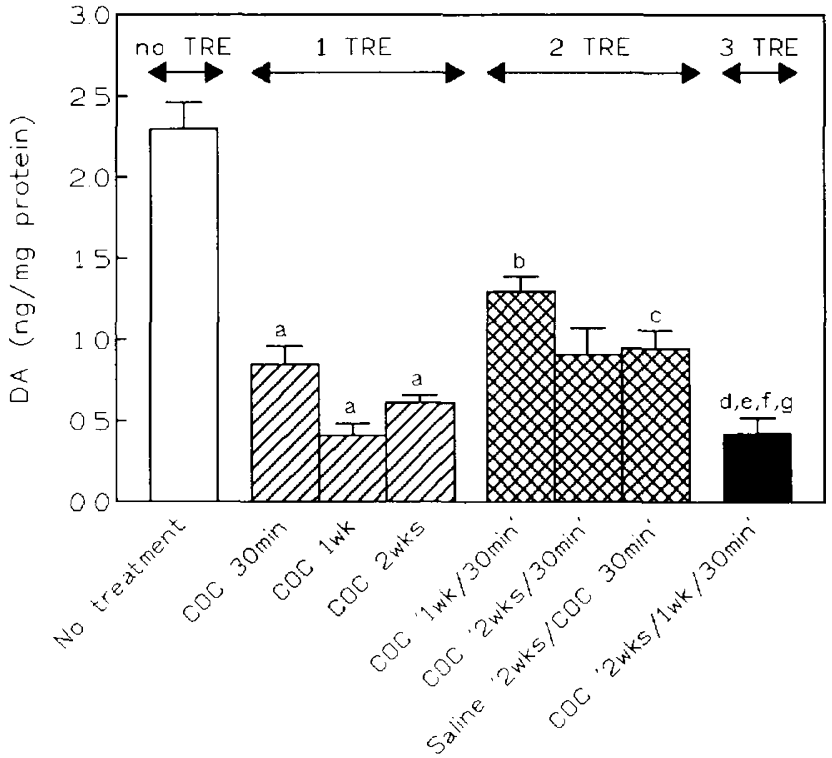

Figure 1. Dopamine efflux from rat brain striatal slices evoked by $10 \mu \mathrm{M}$ amphetamine following IP administration of 15 $\mathrm{mg} / \mathrm{kg}$ cocaine (COC) 30 minutes to 2 weeks before sacrifice. Overall ANOVA $F(7,58)=30.91, p<.001$; $^{a} p<.001$ vs. no treatment (amphetamine alone); ${ }^{\mathrm{b}} p<.01$ vs. COC at 30 minutes; ${ }^{c} p<.02$ vs. COC at 2 weeks; ${ }^{d} p<.001$ vs. COC at 1 week/30 minutes; ${ }^{\mathrm{e}} p<.01$ vs. COC at 2 weeks $/ 30$ minutes; ${ }^{\mathrm{f}} p<.01$ vs. saline at 2 weeks/COC 30 minutes; $\mathrm{g} p<.02 \mathrm{vs}$. COC at 30 minutes. TRE $=$ number of pretreatments. $N=7-9$.

stressors (Antelman and Chiodo 1983; Antelman and Eichler 1979; Antelman et al. 1980, 1989a; Kalivas and Duffy 1989; Kalivas and Stewart 1991; MacLennan and Maier 1983; Robinson 1988; Robinson et al. 1987), we sought to determine whether the reversal we obtained could also be induced by a nondrug stressor. To accomplish this, an injection of isotonic saline, which we have previously shown could induce long-term stressful effects even after a single injection (Antelman et al. $1989 \mathrm{~b}$ ), was administered 2 weeks prior to COC 30 minutes before sacrifice. It significantly reversed the effect of COC administered 2 weeks before sacrifice $(p<$ .02 vs. COC 2 weeks before sacrifice).

Most remarkably, when COC was given at all three time points (i.e., at 2 weeks, 1 week, and 30 minutes before sacrifice), the attenuation observed after only one pretreatment was completely reinstated $(p<.01$ or greater vs. each of the two-pretreatment groups); indeed, it was significantly sensitized (down to $16 \%$ of control; $p<.02$ vs. COC 30 minutes before sacrifice; Figure 1).

The reader might suspect that the decrease in AMevoked DA release induced by COC administered 30 minutes before sacrifice represents tolerance. Indeed, it has been hypothesized that such decreases are a function of high-dose/early-withdrawal-induced tolerance, whereas late-withdrawal paradigms consistently induce enhanced release (Kalivas and Duffy 1993). This formulation cannot explain our findings, since (1) the dose we used is considered a "low" dose (Kalivas and Duffy 1993) and (2) we also obtained a decrease in AMinduced DA release using "late-withdrawal" periods of 1 and 2 weeks following COC. While tolerance can certainly be a factor in some cases of attenuated release, our data indicate that it cannot explain all instances of COC-induced decreases in AM-evoked DA release.
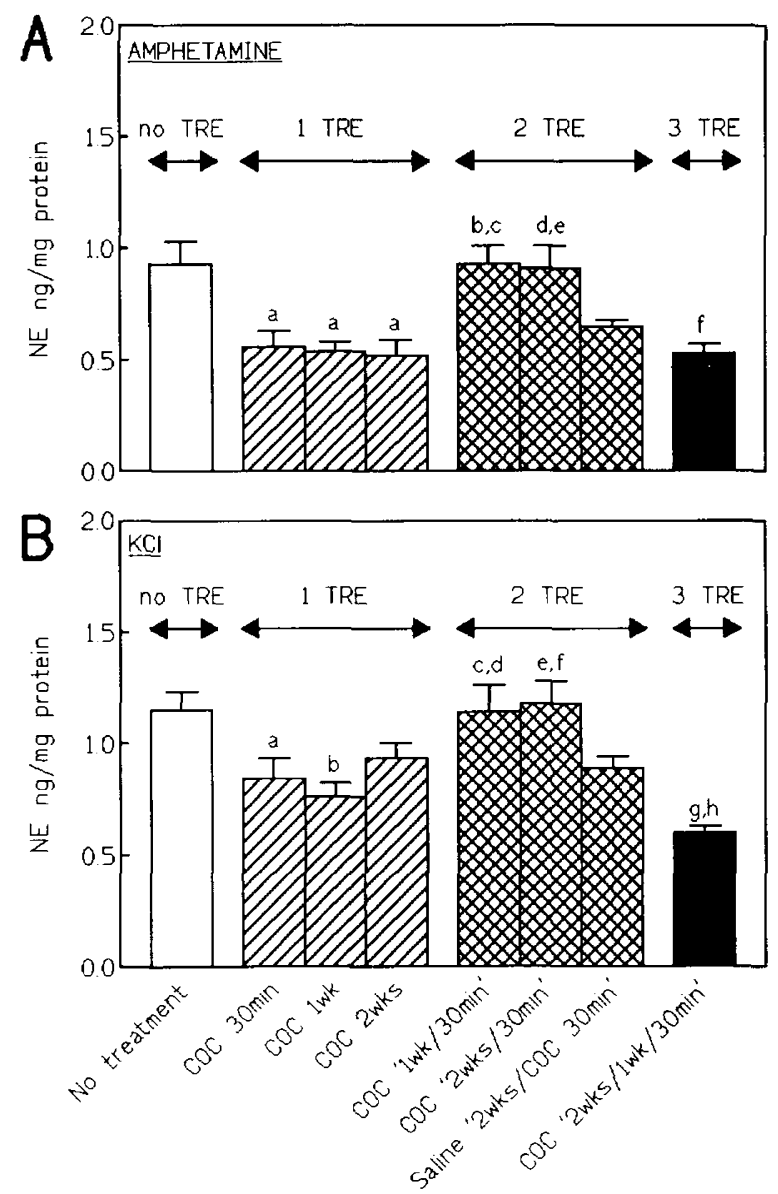

Figure 2. (A) Norepinephrine efflux from the right atrium of rat heart evoked by $10 \mu \mathrm{M}$ amphetamine following $\mathrm{IP}$ administration of $15 \mathrm{mg} / \mathrm{kg}$ cocaine (COC) 30 minutes to 2 weeks before sacrifice. Overall ANOVA $F(7,54)=7.72, p<.001$; ${ }^{a} p<$ .001 vs. no treatment (amphetamine alone); ${ }^{b}$ p .001 vs. COC at 30 minutes; ${ }^{c} p<.001$ vs. COC at 1 week; ${ }^{d} p<.002$ vs. COC at 30 minutes; ${ }^{\mathrm{e}} p<.001$ vs. COC at 2 weeks; ${ }^{\mathrm{f}} p<.001$ vs. COC at 1 week/30 minutes. $N=7-8$. (B) Norepinephrine efflux from the right atrium of rat heart evoked by $25 \mathrm{mM} \mathrm{KCl}$ following IP administration of $15 \mathrm{mg} / \mathrm{kg}$ cocaine (COC) 30 minutes to 2 weeks before sacrifice. Overall ANOVA $F(7,54)=$ $6.96, p<.001 ;{ }^{\mathrm{a}} p<.02$ vs. no treatment $\left(\mathrm{KCl}\right.$ alone); ${ }^{\mathrm{b}} p<$ .002 vs. no treatment $\left(\mathrm{KCl}\right.$ alone); ${ }^{c} p<.02$ vs. $\mathrm{COC}$ at 30 minutes; ${ }^{\mathrm{d}} p<.002$ vs. COC at 1 week; ${ }^{\mathrm{e}} p<.01$ vs. COC at 30 minutes; ${ }^{\mathrm{f}} p<.04$ vs. COC at 2 weeks; $\mathrm{g} p<.001$ vs. COC at 1 week/30 minutes; ${ }^{h} p<.04$ vs. COC at 30 minutes. TRE $=$ number of pretreatments. $N=7-8$. 
Elsewhere, we have suggested that the direction of a drugs effect on physiological systems depends on the initial sensitivity of the systems being affected (Antelman et al. 1991), and we have recently shown that the same COC pretreatment used here increases DA efflux when initial sensitivity is low (Caggiula et al. 1994).

\section{Experiment 2: Effects of Sequential Cocaine Administration on Amphetamine and $\mathrm{K}^{+}$-Evoked Efflux of Heart Norepinephrine and on Nonevoked Plasma Corticosterone and Glucose}

Procedure. We enquired next whether the results obtained in Experiment 1 were limited to DA neurons in the striatum. We therefore repeated the design of the first experiment for AM-evoked NE release from the right atrium of the heart (Figure 2A). In addition, in this experiment, following AM-evoked release we also measured $\mathrm{K}^{+}$-evoked NE release in the same tissue (Figure $2 \mathrm{~B}$ ).

Results and Discussion. Repeated COC administration produced an essentially identical pattern of results to that seen for DA. Cocaine administered once, 30 minutes, 1 week, or 2 weeks before sacrifice, significantly reduced AM-evoked efflux of heart NE to 56 to $60 \%$ of control. Norepinephrine efflux was completely normalized in the 2-COC groups [i.e., both the COC 1-week/30-minute and COC 2-week/30-minute groups

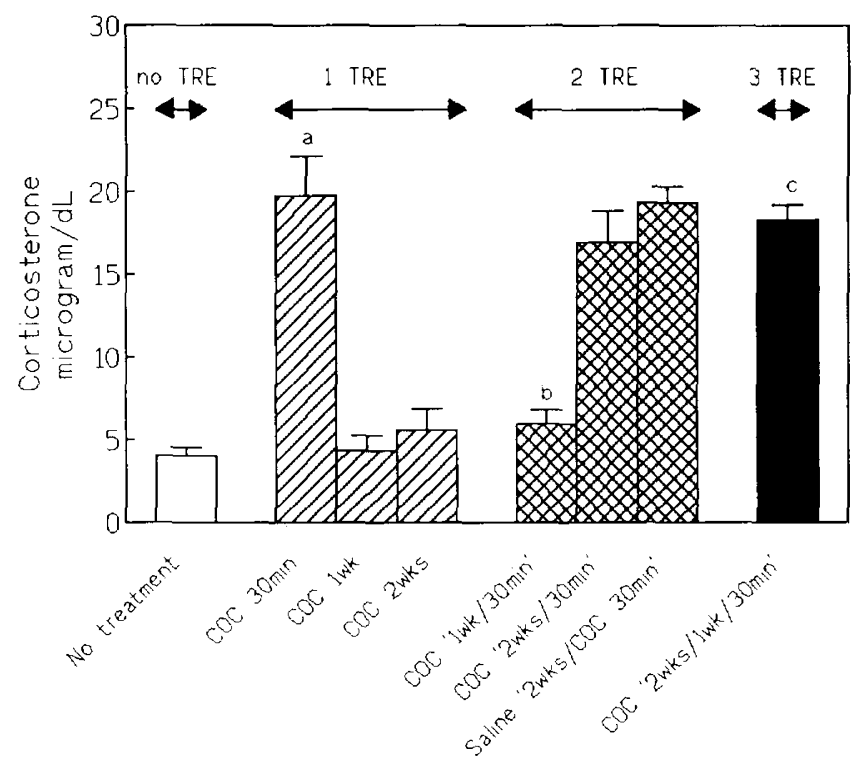

Figure 3. Plasma corticosterone following IP administration of $15 \mathrm{mg} / \mathrm{kg}$ cocaine (COC) 30 minutes to 2 weeks before sacrifice. Overall ANOVA $F(7,65)=30.34, p<.001 ;^{a} p<.001$ vs. no treatment (No TRE = basal levels of corticosterone); ${ }^{\mathrm{b}} p<.001$ vs. COC at 30 minutes; ${ }^{c} p<.001$ vs. COC at 1 week $/ 30$ minutes. TRE $=$ number of pretreatments. $N=$ 9-10.
( $100 \%$ and $98 \%$ of control, respectively)]. Once again, as with striatal DA efflux, when COC was given three times, at 2 weeks, 1 week, and 30 minutes before sacrifice, the NE decrease seen after a single COC treatment was reinstated back down to $57 \%$ of control $(p<$ .001 vs. the 2 -COC groups). The same pattern of results was obtained when $\mathrm{K}^{+}$was used as the releasing agent (Figure 2B). The fact that the oscillatory effect was obtained on transmitter efflux using both $\mathrm{Ca}^{++}$and impulse-dependent $\left(\mathrm{K}^{+}\right)$and -independent (AM) methods (Jacocks and Cox 1992) suggests that it is physiologically significant and not simply a pharmacological phenomenon.

Additional measurements in this experiment indicated that the effects described were neither unique to the in vitro efflux procedure or to transmitters, since basically the same results were obtained for plasma CORT and GLUC levels (Figures 3 and 4). Corticosterone and GLUC were measured as indices of the stressfulness of our procedures and determined in the same animals to which COC had been given.

As expected, COC administered 30 minutes prior to sacrifice markedly elevated both CORT $(490 \%$ of control; $p<.001$ vs. no treatment $)$ and GLUC $(152 \%$ of control; $p<.001$ vs. no treatment). However, when COC pretreatments were given at both 1 week and 30 minutes, the CORT and GLUC elevations observed at 30 minutes were significantly attenuated. Corticosterone elevation decreased precipitously, down to $149 \%$ of control ( $p<.001$ vs. COC at 30 minutes), while GLUC dropped to $126 \%$ of control ( $p<.004$ vs. COC at 30 minutes). As was the case with striatal DA, a similar reversal for GLUC (down to $120 \%$ of control) was seen when a nondrug stressor (again a saline injection) preceded the 30 -minute COC treatment by 2 weeks ( $p<$ .001 vs. COC at 30 minutes). Moreover, exactly as occurred with DA and NE release, when the 2-week, 1-week, and 30-minute COC treatments were linked, the effect of two COC treatments was itself reversed and the elevated CORT and GLUC seen in the 30-minute group, was almost precisely reinstated (to $456 \%$ and $151 \%$ of control; $p<.001$ and $p<.005$ vs. COC at 1 week and 30 minutes for CORT and GLUC, respectively).

When two treatments were separated by a 2-week interval there was no significant reversal of CORT or GLUC in three out of four instances. However, significant reversals at 2 weeks were observed in five of eight instances in Experiments 1, 2, and 4 in this article and seven out of eight in experiments reported in a paper involving the effects of ETOH pretreatment on DA efflux (Caggiula et al. submitted). In contrast to the above, there was $100 \%$ reversal $(6 / 6)$ when a 1 -week interval between treatments was used. Although the numbers are too small to draw firm conclusions, this pattern might suggest that reversals are more likely to occur with shorter intervals between treatments. 
Figure 4. Plasma glucose following IP administration of $15 \mathrm{mg} / \mathrm{kg}$ cocaine (COC) 30 minutes to 2 weeks before sacrifice. Overall ANOVA $F(7,65)=$ $14.20, p<.001$; ${ }^{a} p<.001$ vs. no treatment (No TRE $=$ basal levels of glucose) $;{ }^{b} p<.004$ vs. COC at 30 minutes; ${ }^{\mathrm{c}} p<.001$ vs. COC at 30 minutes; ${ }^{\mathrm{d}} p<.005$ vs. COC at 1 week $/ 30$ minutes. TRE $=$ number of pretreatments. $N=9-10$.

Experiment 3: Amphetamine-Evoked Efflux of Striatal Dopamine after Partial Substitution of a Non-drug Stressor for Sequential Cocaine Administration

Rationale and Procedure. Some of the results with saline suggested the involvement of stress in oscillation (Figures 1 and 4 above; see also Figure 5B), whereas others did not (Figures 2 and 3). This could have been due to saline having been administered 2 weeks prior to $C O C$, a time when, as already noted, $C O C$ itself was not always effective in reversing subsequent $\mathrm{COC}$ treatment (in contrast to the uniform effectiveness of $\mathrm{COC}$ treatments spaced only 1 week apart). To clarify the potential involvement of stress, we inquired whether a traditionally stronger, nonpharmacological stressor, immobilization (administered for 10 minutes by wrapping in muslin), inserted between two COC treatments and flanked by one-week intervals, would result in the same pattern of AM-induced release of DA from the striatum as three $\mathrm{COC}$ treatments. Animals were grouped according to five different pretreatment conditions. These were: no pretreatment controls, COC 30 minutes before sacrifice, COC 1 week and 30 minutes before sacrifice, COC 2 weeks, 1 week, and 30 minutes before sacrifice and COC 2 weeks, immobilization 1 week and COC 30 minutes before sacrifice. The reader will note that the first four groups in this experiment were exposed to the identical conditions as those depicted in Figure 1, only in different animals, 9 months later. Thus, in addition to addressing the issue of stress involvement, this experiment also served as a means of validating the findings graphed on Figure 1.

Finally, it seems apparent to us that data so distinctively different from traditional sensitization findings and potentially important for a fuller understanding of
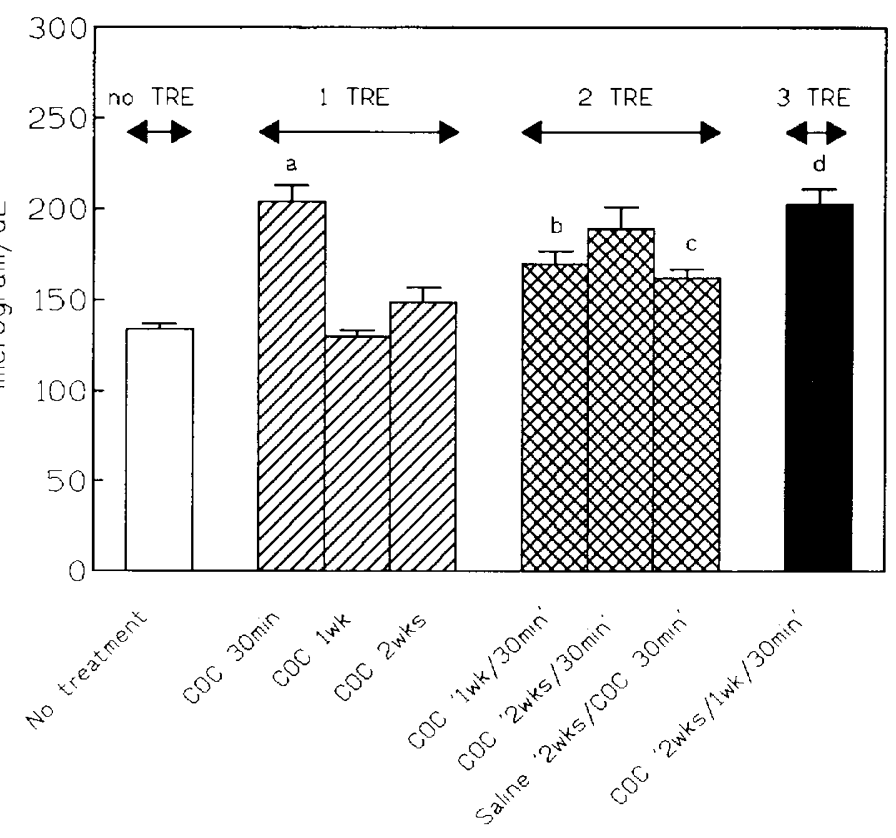

the actions of COC are likely to encounter substantial barriers to acceptance from many quarters. Therefore, in an effort to avoid some of these anticipated difficulties, we took the unusual step of repeating Experiment 1 in its entirety in a completely blind fashion, a full 2 years after it was originally done (June 1994 vs. June 1992).

Results and Discussion. The results of substituting a nondrug stressor for $\mathrm{COC}$ are seen in Figure 5A. Exactly as observed in the first experiment, 1 COC pretreatment significantly decreased AM-induced striatal DA release ( $p<.001$ vs. AM without pretreatment), and this effect was significantly reversed by two COC pretreatments ( $p<.03$ vs. COC at 30 minutes) and reinstated by three pretreatments $(p<.002$ vs. COC at 1 week and 30 minutes), which, as before, resulted in a significantly greater (i.e., a sensitized) decrease in release than a single COC pretreatment $(p<.01$ vs. COC at 30 minutes). Most important, the group that was exposed to an immobilization stress sandwiched between 2 COC pretreatments looked as though it had received three COC treatments and differed significantly from animals receiving only two administrations of $\operatorname{COC}(p<$ $.002)$.

The results of the replication of Experiment 1 are presented in Figure 5B. Yet again, the basic pattern of response oscillation after successive administrations of COC obtained in the original experiment, is repeated. One COC treatment 30 minutes, 1 week, or 2 weeks earlier significantly reduced AM-evoked efflux of DA from striatal slices down to $28 \%$ to $35 \%$ of control ( $p<$ .001 vs. AM alone in all cases). These decreases in DA efflux were significantly reversed back to $72 \%, 70 \%$, and $64 \%$ of control, respectively, in groups receiving two COC pretreatments at 1 week and 30 minutes and 2 

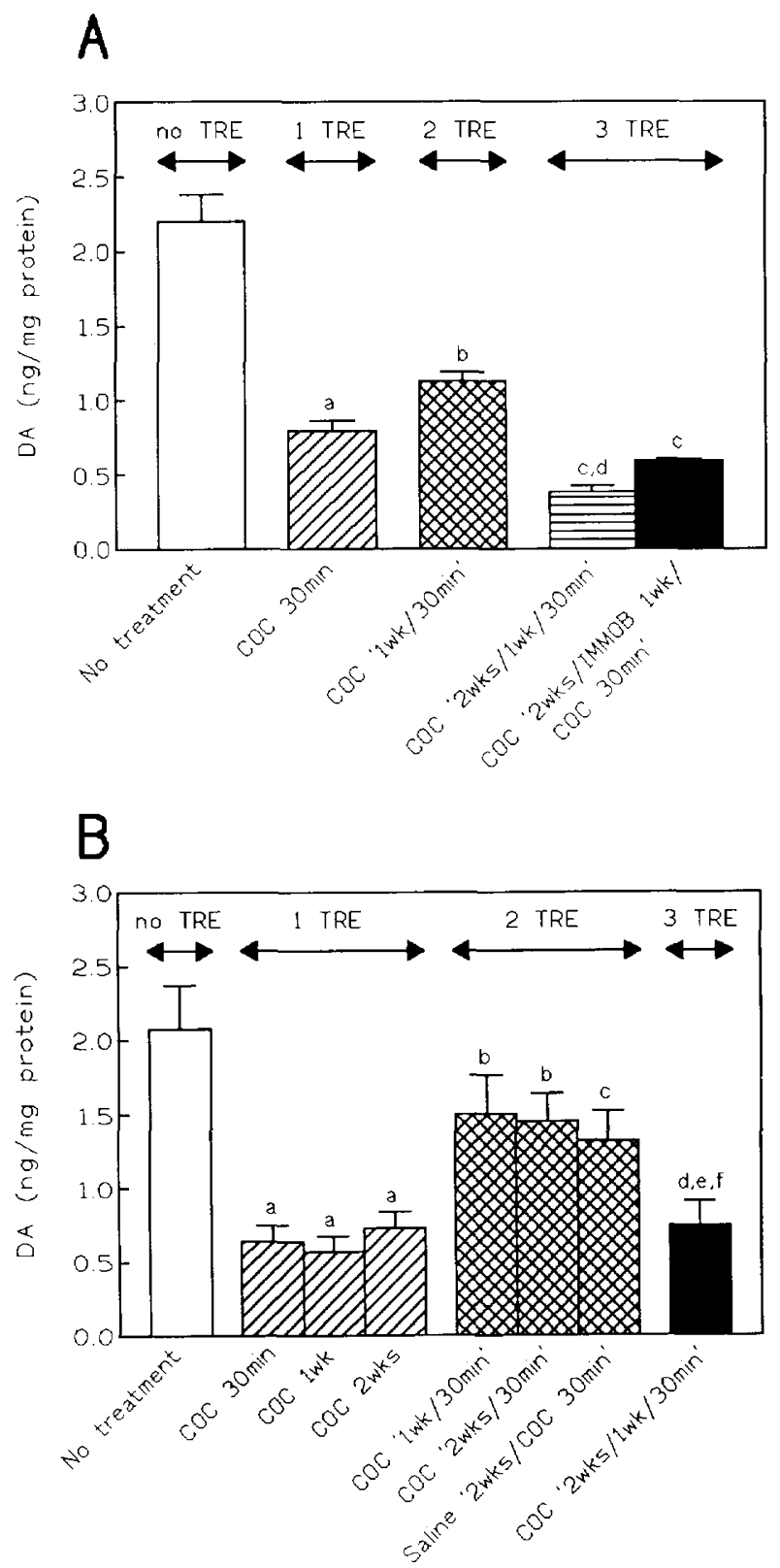

Figure 5. (A) Ten minutes of immobilization (IMMOB) stress by wrapping in muslin was completely interchangeable with $15 \mathrm{mg} / \mathrm{kg}$ IP of cocaine (COC) in sustaining oscillation induced by sequential pretreatment with COC 2 weeks, 1 week, and 30 minutes before sacrifice. The measurement is dopamine efflux from rat brain striatal slices evoked by $10 \mu \mathrm{M}$ amphetamine. Overall ANOVA $F(4,31)=51.96, p<.001$; ${ }^{a} p<.001$ vs. no treatment (amphetamine alone); ${ }^{b} p<.03$ vs. COC at 30 minutes; ${ }^{c} p<.002$ vs. COC at 1 week/30 minutes; ${ }^{d} p<$ .01 vs. COC at 30 minutes. $N=6-8$. (B) Dopamine efflux from rat brain striatal slices evoked by $10 \mu \mathrm{M}$ amphetamine following IP administration of $15 \mathrm{mg} / \mathrm{kg}$ cocaine (COC) 30 minutes to 2 weeks before sacrifice. Overall ANOVA $F(7,61)=$ $8.25, p<.001$; ${ }^{a} p<.001$ vs. no treatment (amphetamine alone); ${ }^{b} p<.005$ vs. COC at 30 minutes; ${ }^{c} p<.02$ versus COC at 30 minutes; ${ }^{d} p<.007$ vs. COC at 1 week $/ 30$ minutes; e $p<.02$ vs. COC at 2 weeks $/ 30$ minutes; ${ }^{\mathrm{f}} p<.05$ vs. saline at 2 weeks $/ C O C 30$ minutes. TRE $=$ pretreatments. $N=7-9$. weeks and 30 minutes (each $p<.005$ vs. COC at 30 minutes) as well as in the group receiving saline at 2 weeks and COC at 30 minutes prior to sacrifice $(p<$ .03 vs. COC at 30 minutes). As in Figures 1 and $5 \mathrm{~A}$, the addition of a third $C O C$ pretreatment significantly reversed the influence of all two pretreatment combinations ( $p<.007-.05$; see Figure 5B legend for details) and reinstated the greater decline in DA efflux (down to $36 \%$ of control) that occurred after only one COC pretreatment. Only the sensitization seen in Figures 1 and $5 \mathrm{~A}$, when the effects of three COC pretreatments were compared to one, was not observed here.

\section{GENERAL DISCUSSION}

Our findings demonstrate that the effects of single COC pretreatment on an array of physiological measures (striatal DA and heart NE efflux and plasma levels of CORT and GLUC) were offset by chaining two COC pretreatments and reinstated by a three-treatment chain (i.e., they oscillated). In other words, successive drug administrations acted as a binary switch mechanism, toggling the physiological effects forth and back. This suggests that there may be an inherent variability in the way physiological systems respond to repeated drug treatment. The diversity of endpoints for which oscillation was shown provides strong indications that it is a general phenomenon, possibly applicable to most physiological systems. Indeed, in addition to the results described here, we have also demonstrated oscillation for $\mathrm{D}-\left[{ }^{3} \mathrm{H}\right]$ aspartate efflux from the medial frontal cortex (Caggiula et al. submitted) and ${ }^{3} \mathrm{H}$-acetylcholine efflux from the heart (Somogyi et al. unpublished observations). Specifically as it relates to COC, the cyclic vulnerability in response to successive administrations of this agent may account for its often-seen variable and unpredictable effects, such as both increasing and decreasing DA release (e.g., Kalivas and Duffy 1993; Segal and Kuczenski 1992a, 1992b; Zahniser and Peris 1992) and both inducing and protecting against sudden cardiac death (Antelman et al. 1981, 1989a).

While the results demonstrate an alternation in drug effects with successive administrations, they were obtained using long intervals between treatments. The length of the intertreatment intervals raises the question of the applicability of our findings to a standard therapeutic regimen of three times daily administration. A very recent experiment from our lab provides a positive answer by showing that identical results on striatal DA release were obtained when three AM pretreatments were spaced at 2-hour intervals (Antelman et al. unpublished observations).

The finding that nonpharmacological stressorsimmobilization and an injection of saline - could substitute for COC in reproducing many of the oscillation 
effects indicates that this phenomenon occurs as a consequence of the stressful/foreign nature of drugs - as is the case with sensitization (Antelman 1988; Antelman et al. 1992b) - rather than because of their unique pharmacological properties. As such, it is likely to be seen with drugs differing markedly in their pharmacological actions and clinical intent. This view is supported by the observation noted that ETOH could similarly induce oscillation (Antelman et al. 1992a; Caggiula et al. submitted).

The cycling or oscillation effect reported here may apply not only to variability in responsiveness between individuals but also to variability within the same individual from one time to the next. The latter is seen most prominently in the many human clinical disorders that frequently manifest a dramatic cyclicity or oscillation in magnitude or even direction of symptoms during pharmacological treatment or exposure to nondrug stressors. Oscillation of physiological systems in responsiveness to stressors may be a core factor that, when exacerbated, leads to cyclic clinical syndromes. Among the most apparent of these are: (1) the switches between mania and depression in bipolar affective disorder as well as recurrent episodes of depression in unipolar disorder; (2) the rapid "on-off" alternation between immobility and periods of normality or dyskinesia often seen during chronic pharmacological treatment of Parkinson's disease; (3) the alternation between symptoms of intrusive reexperiencing of traumatic events and numbing/avoidance symptoms in posttraumatic stress disorder; (4) fluctuations in ACTH and cortisol levels in cyclic Cushing's disease; (5) fluctuations in peptic ulcers; and (6) periodic paralyses (Arnold 1985; Bunney and Murphy 1974; Klawans and Weiner 1981; Horowitz 1976; Reus and Berlant 1986; Rudel and Ricker 1985; Sonnenberg et al. 1992; Stoddard et al. 1977; Sweet and McDowell 1974; Yahr 1974).

Our results could have important implications for understanding the physiological underpinnings of persistent drug-taking behavior. It is well-established that when drugs are administered continuously or at very short intervals, rapid tolerance tends to develop, whereas sustained effects are much more likely with intermittent exposure (Antelman 1988; Antelman et al. 1992b; Post 1980). The cyclicity reported here may provide physiological concomitants of an intermittent schedule of drug effects. In turn, the compulsory intermittency imposed on the organism by oscillation of physiological systems could be an important factor in COC's addictive potential.

It is also important to note the similarity between oscillation and sensitization. Both are induced by drugs and nonpharmacological stressors, affect an array of physiological systems, and are extremely long-lasting (Antelman 1988; Antelman et al. 1992a, 1992b). These and other similarities lead us to suggest that sensitiza- tion to stressors would be expected when a system is well within its physiological boundaries or limits, whereas oscillations or resetting of systems is more likely to occur when those boundaries are approached. Inherent in the question of the relationship between response sensitization and response oscillation is the more fundamental issue of whether systems can sensitize indefinitely or whether at some point countervailing mechanisms are activated by the organism in an attempt to maintain homeostasis. Although to our knowledge this issue has not been addressed previously, the possibility that sensitization can indeed go on indefinitely makes little sense, since all biological systems have their limits or boundaries. We would propose that increasingly more aggressive sensitization regimes would lead to greater sensitization - as has been found - up to the point where oscillation occurs. Since, as seems probable, any given study is likely to have individuals in both sensitization and oscillation phases, this schema would predict the enormous individual variation that characterizes sensitization (see Robinson 1988 for discussion of this issue). An example of a system resetting when it nears its physiological limits may be the depolarization blockade that is known to occur in DA neurons following their excessive activation by repeated neuroleptic treatment (Bunney and Grace 1978). Other such examples may be found in the law of initial values and paradoxic reaction that predicts a reversal in the direction of stress effects when extreme levels of high or low initial reactivity are approached (Wilder 1962).

Finally, it is critical to address the question of why the data reported here at first glance appear so different from what would be expected from most of the literature on sensitization. In so doing it needs to be pointed out that since virtually all sensitization experiments of which we are aware compare only the effects of acute versus chronic COC or AM and perform their neurochemical measurements solely after these regimes have been completed, they obviate the possibility of observing any "on-off" oscillatory pattern that might have occurred in their animals during a chronic regime. In contrast, our protocol does not use the traditional, acute-versus-chronic comparison. Instead, measurements are made after each of however many COC treatments are administered. This procedure puts us in a better position to observe animals either in the "on-off" oscillatory phase or in the process of moving from a unidirectional, sensitization pattern to an oscillatory pattern of response.

\section{ACKNOWLEDGMENT}

Supported by grants MH24114, P50AA08746, and DA07546. 


\section{REFERENCES}

Antelman SM (1988): Time-dependent sensitization as the cornerstone for a new approach to pharmacotherapy: Drugs as foreign/stressful stimuli. Drug Dev Res 14:1-30

Antelman SM, Eichler AJ (1979): Persistent effects of stress on dopamine-related behaviors: Clinical implications. In Usdin E, Kopin IJ, Barchas J (eds), Catecholamines: Basic and Clinical Frontiers, Elmsford, NY, Pergamon Press, pp 1759-1761

Antelman SM, Eichler AJ, Black CA, Kocan D (1980): Interchangeability of stress and amphetamine in sensitization. Science 207:329-331

Antelman SM, Kocan D, Rowland N, DeGiovanni L, Chiodo LA (1981): Amitriptyline provides long-lasting immunization against sudden cardiac death from cocaine. Eur J Pharm 69:119-120

Antelman SM, Chiodo LA (1983): Amphetamine as a stressor. In Creese I (ed), Stimulants: Neurochemical, Behavioral and Clinical Perspectives, New York, Raven Press, pp 269-299

Antelman SM, DeGiovanni LA, Kocan D (1989a): A single exposure to cocaine or immobilization stress provides extremely long-lasting, selective protection against sudden cardiac death from tetracaine. Life Sciences 44:201-207

Antelman SM, Kocan D, Edwards DJ, Knopf S (1989b): Anticonvulsant and other effects of diazepam grow with time after a single treatment. Pharmacol Biochem Behav 33:31-39

Antelman SM, Caggiula AR, Kocan D, Knopf S, Meyer D, Edwards DJ, Barry III H (1991): One experience with "lower" or "higher" intensity stressors, respectively, enhances or diminishes responsiveness to haloperidol weeks later: Implications for understanding drug variability. Brain Res 566:276-283

Antelman SM, Caggiula AR, Edwards DJ, Kiss S, Kocan D, Barry III H (1992a): Acute stress or ethanol (ETOH) can have a very long lasting influence on in vitro dopamine (DA) release from striatal slices. Neuroscience Abstr 18:203

Antelman SM, Caggiula AR, Knopf S, Kocan DJ, Edwards DJ (1992b): Amphetamine or haloperidol 2 weeks earlier antagonized the plasma corticosterone response to amphetamine: Evidence for the stressful/foreign nature of drugs. Psychopharmacology 107:331-336

Arnold AL (1985): Diagnosis of post-traumatic stress disorder in Vietnam Veterans. In Sonnenberg SM, Blank Jr AS, Talbott JA (eds), The Trauma of War: Stress and Recovery in Vietnam Veterans, Washington, DC American Psychiatric Press, pp 99-123

Bell DS (1973): The experimental reproduction of amphetamine psychosis. Arch Gen Psychiatry 29:35-40

Bunney BS, Grace AA (1978): Acute and chronic haloperidol treatment: Comparison of effects on nigral dopaminergic cell activity. Life Sci 23:1715-1727

Bunney Jr WE, Murphy DL (1974): Switch processes in psychiatric illness. In Kline NS (ed), Factors in Depression, New York, Raven, pp 139-158

Caggiula AR, Antelman SM, Edwards DJ, Kiss S, Kocan D, Stiller R (1994): Oscillatory effects of cocaine on dopa- mine efflux in rats. Society for Neuroscience Abstract \#664.16

Connell PH (1958): Amphetamine Psychosis, London, Oxford University Press

Horowitz MJ (1976): Stress Response Syndromes, New York, Jason Aronson

Jacocks III HM, Cox BM (1992): Serotonin-stimulated release of $\left[{ }^{3} \mathrm{H}\right]$ dopamine via reversal of the dopamine transporter in rat striatum and nucleus accumbens: A comparison with release elicited by potassium, N-methylD-aspartic acid, glutamic acid and D-amphetamine. J Pharmacol Exp Therap 262:356-364

Kalivas PW, Duffy P (1989): Similar effects of daily cocaine and stress on mesocorticolimbic dopamine transmission in the rat. Biol Psychiatry 25:913-928

Kalivas PW, Duffy P (1993): Time course of extracellular dopamine and behavioral sensitization to cocaine. I. Dopamine axon terminals. J Neuroscience 13:266-275

Kalivas PW, Stewart J (1991): Dopamine transmission in the initiation and expression of drug- and stress-induced sensitization of motor activity. Brain Res Rev 16:223-244

Klawans HL, Weiner W (1981): Textbook of Clinical Neuropharmacology, New York, Raven

Lowry OH, Rosebrough NJ, Farr AL, Randall RJ (1951): Protein measurement with folin phenol reagent. J Biol Chemistry 193:265-275

MacLennan AJ, Maier SF (1983): Coping and the stressinduced potentiation of stimulant stereotypy in the rat. Science 219:1091-1093

Murphy BE (1967): Some studies on the protein-binding of steroids and their application to the routine micro and ultramicro measurement of various steroids in body fluids by competitive protein-binding radioassay. J Clin Endocrinol Metab 27:973-990

Post RM (1980): Intermittent versus continuous stimulation: Effect of the interval on the development of sensitization or tolerance. Life Sciences 26:1275-1282

Ranje C, Ungerstedt U (1974): Chronic amphetamine treatment: Vast individual differences in performing a learned response. Eur J Pharmacology 29:307-311

Reus VI, Berlant JR (1986): Behavioral disturbances associated with disorders of the hypothalamic-pituitary-adrenal system. In Extein I, Gold MS (eds), Medical Mimics of Psychiatric Disorders, Washington, DC, American Psychiatric Press, pp 113-130

Robinson TE (1988): Stimulant drugs and stress: Factors influencing individual differences in the susceptibility to sensitization. In Kalivas PW, Barnes CD (eds), Sensitization in the Nervous System, Caldwell, N.J., The Telford Press, pp 145-173

Robinson TE, Becker JB (1986): Enduring changes in brain and behavior produced by chronic amphetamine administration: A review and evaluation of animal models of amphetamine psychosis. Brain Res Rev 11:157-198

Robinson TE, Becker JB, Young EA, Akil H, Castaneda E (1987): The effects of footshock stress on regional brain dopamine metabolism and pituitary beta-endorphin release in rats previously sensitized to amphetamine. Neuropharmacology 26:679-691 
Rudel R, Ricker K (1985): The primary periodic paralyses. Trends in Neurosciences 8:467-470

Segal DS, Kuczenski R (1992a): In vivo microdialysis reveals a diminished amphetamine-induced DA response corresponding to behavioral sensitization produced by repeated amphetamine pretreatment. Brain Res 571: 330-337

Segal DS, Kuczenski R (1992b): Repeated cocaine administration induces behavioral sensitization and corresponding decreased extracellular dopamine responses in caudate and accumbens. Brain Res 577:351-355

Snyder GL, Keller Jr RW, Zigmond MJ (1990): Dopamine efflux from striatal slices after intracerebral 6-hydroxydopamine: Evidence for compensatory hyperactivity of residual terminals. J Pharmacol Exp Ther 253:867-876

Sonnenberg A, Wasserman IH, Jacobsen SJ (1992): Monthly variation of hospital admission and mortality of peptic ulcer disease: A reappraisal of ulcer periodicity. Gastroenterology 103:1192-1198

Stoddard FJ, Post RM, Bunney Jr WE (1977): Slow and rapid psychobiological alterations in a manic-depressive patient: Clinical phenomenology. Brit J Psychiat 130:72-78
Sweet RD, McDowell FH (1974): The "on-off" effect response to chronic L-DOPA treatment of parkinsonism. In McDowell FH, Barbeau A (eds), Advances in Neurology (vol. 5), New York, Raven, pp 331-338

Trinder P (1969): Determination of blood glucose using 4-amino phenazone as oxygen acceptor. J Clin Path 22:246-250

Van Dyke C, Byke R (1977): Cocaine 1884-1974. In Ellinwood EH, Kilbey M (eds), Cocaine and Other Stimulants, New York, Plenum, pp 1-30

Wilder J (1962): Basimetric approach (law of initial value) to biological rhythms. Ann N Y Acad Sci 98:1211-1220

Yahr MD (1974): Variations in the "on-off" effect. In McDowell FH, Barbeau A (eds), Advances in Neurology (vol. 5), New York, Raven, pp 397-399

Zahniser NR, Peris J (1992): Neurochemical mechanisms of cocaine-induced sensitization. In Lakoski JM, Galloway MP, White FJ (eds), Cocaine: Pharmacology, Physiology, and Clinical Strategies, Boca Raton, FL, CRS Press, pp 229-260 